\title{
Increasing Engineering Students' Awareness to Environment through Innovative Teaching of Mathematical Modelling
}

\author{
Sergiy Klymchuk*, Tatyana Zverkova**, Norbert Gruenwald*** and Gabriele \\ Sauerbier*** \\ *Auckland University of Technology, Auckland, New Zealand \\ **Odessa National University, Odessa, Ukraine \\ ***Wismar University of Technology, Business and Design, Wismar, Germany
}

\begin{abstract}
This paper presents the results of two studies on using an innovative pedagogical strategy in teaching mathematical modelling and applications to engineering students. Both studies are dealing with introducing non-traditional for engineering students contexts in teaching/learning of mathematical modelling and applications: environment and ecology. The aims of using these contexts were: to introduce students to some of the techniques, methodologies and principles of mathematical modelling for ecological and environmental systems; to involve the students in solving real-life problems adjusted to their region emphasising the aspects of both survival (short term) and sustainability (long term); to encourage students to pay attention to environmental issues. On one hand, the contexts are not directly related to engineering. On the other hand, chances are that most of the graduates in engineering will be dealing with mathematical modelling of environmental systems in one way or another in their future work because nearly every engineering activity has an impact on the environment. The first study is a parallel study conducted in New Zealand and Germany simultaneously with first-year students studying engineering mathematics. The second study is a case study based the experimental course Mathematical Modelling of Survival and Sustainability taught to a mixture of year 2-5 engineering students in Germany by a visiting lecturer from New Zealand. The models used with the students from both studies had several special features. Analysis of students' responses to questionnaires, their comments and attitudes towards the innovative approach in teaching are presented in the paper.
\end{abstract}

\section{Introduction}

There are many papers devoted to investigating undergraduate students' competency in the mathematical modelling process. We mention some recent research. A measure of attainment for stages of modelling has been developed in (Haines \& Crouch, 2001) The authors expanded their study in (Crouch \& Haines, 2004) where they compared undergraduates (novices) and engineering research students (experts). They suggested a three level classification of the developmental processes which the learner passes in moving from novice behaviour to that of an expert. One of the conclusions of that research was that "students are weak in linking mathematical world and the real world, thus supporting a view that students need much stronger experiences in building real world mathematical world connections" (Crouch \& Haines, 2004). It echoes with the findings from a study of 500 students from 14 universities in Australia, Finland, France, New Zealand, Russia, South Africa, Spain, Ukraine and the UK (Klymchuk \& Zverkova, 2001). The study indicated that the students felt difficult to move from the 
real world to the mathematical world because of the lack of practice in application tasks. An investigation of undergraduate students' working styles in a mathematical modelling activity has been done in (Maull \& Berry, 2001) and a study on the development of transferable skills in undergraduate mathematics students through mathematical modelling in (Nyman \& Berry, 2002). Some relationships between students' mathematical competencies and their skills in modelling were considered in (Galbraith \& Haines, 1998) and in (Gruenwald \& Schott, 2000). Kadijevich pointed out at an important aspect of doing even simple mathematical modelling activity by new coming undergraduate students: “Although through solving such ... [simple modelling] ... tasks students will not realise the examined nature of modelling, it is certain that mathematical knowledge will become alive for them and that they will begin to perceive mathematics as a human enterprise, which improves our lives” (Kadijevich, 1999).

In this paper we consider engineering students' feedback on introducing non-traditional for them contexts in teaching/learning of mathematical modelling and applications: environment and ecology. On one hand, the contexts are not directly related to engineering. On the other hand, chances are that most of the graduates in engineering will be dealing with mathematical modelling of environmental systems in one way or another in their future work because nearly every engineering activity has an impact on the environment. By involving the students in solving real-life problems adjusted to their region with emphasis on survival (short term) and sustainability (long term) we encourag them to pay attention to environmental issues. We present the results of two studies spanned over the period 2005-2007. The models used with the students in both studies have the following features:

- Each model is environmental. Environmental issues are getting more and more important for many human activities worldwide. This, on the first glance nontraditional area of application for engineering students, will help them to broaden their vision and prepare them to take ethical responsibility in future because nearly every engineering activity relates to the environment.

- Each model is adjusted to the region where the students study by selecting a nearby lake or an island, putting its name in the title of the model and entering the corresponding values of the parameters into the model. We assume that this psychological strategy will help students to relate to the models in a personal and an emotional way and increase their motivation and enthusiasm.

- Each model is developed by professional mathematicians working in industry and is based on a real practical problem.

- Each model is adapted and presented in a way understood by engineering students.

- Each model is a little bit beyond the scope of the mathematics course the students study. So they need to learn on their own some new concepts. For example, a model can be based on separable differential equations that students study but further investigation of equilibrium solutions and stability that are not covered in the course is required. We assume that this discovery learning strategy can help the students enhance their investigation and research skills.

- Each model is mathematized to a large extend. So the students do not go through the first few steps of mathematical modelling process (collecting the data, making 
assumptions, formulating the mathematical model, etc.). But, apart from solving the given mathematical models, they do practice in other important steps of mathematical modelling process including interpreting the solutions, discussing the limitations of the models and communicating the findings through a written report.

In both studies, practice was selected as the basis for the research framework and, it was decided 'to follow conventional wisdom as understood by the people who are stakeholders in the practice' (Zevenbergen \& Begg, 1999). The students' mathematical and modelling activities in the class as well as their attitudes were the research objects.

\section{The First Study}

The first study was conducted simultaneously with the first-year engineering students studying mathematics courses in the Auckland University of Technology, New Zealand and the Wismar University of Technology, Business and Design, Germany. Two environmental models were given to the students as a project/assignment. One of the models is given below.

\section{Model of Water Quality Control in Taupo Lake}

Polluted water enters Taupo lake from a recently built factory at a constant rate $N$. A mathematical model of concentration of pollution has been developed under certain assumptions including the following:

- the upper levels of water are mixed in all directions

- change in mass of pollution is equal to the difference between the mass of the entering pollution and the mass of the pollution which is being decomposed

- the rate of decomposition of pollution is constant

- decomposition of pollution takes place due to biological, chemical and physical processes and/or exchange with the deeper levels of water.

Under the assumptions the equation of the balance of mass of pollution on any interval of time $\Delta t$ can be written in the form:

$$
V \Delta C_{N}=N \Delta t-Q C_{N} \Delta t-K V C_{N} \Delta t \text {, }
$$

where $V$ - volume of the upper levels (constant), $Q$ - water consumption rate (constant), $C_{N}=C_{N}(t)$ - concentration of pollution at time $t, K$ - decomposition rate (constant).

Questions:

1. Set up a differential equation for the concentration of pollution from equation (1) by dividing both sides of equation (1) by $\Delta t$ and taking a limit when $\Delta t \rightarrow 0$.

2. Solve that differential equation to find the concentration of pollution as a function of time provided that the initial concentration of pollution was zero.

3. Determine the equilibrium concentration of pollution $C_{\mathrm{Ne}}$ (that is the

$$
\text { concentration when } \left.t \rightarrow \infty \text { or } \frac{d C_{N}}{d t}=0\right) \text {. }
$$


4. Determine time needed to reach $p$ portion $\left(p=C_{N}(t) / C_{N e}\right)$ of the equilibrium concentration. Will it take more time to reach $p$ portion of the equilibrium concentration in case when there is no decomposition of pollution?

5. Set up a differential equation for the concentration of pollution from the differential equation in question 1 in case when the initial amount of pollution entered the lake was $C_{o}$ and after that pollution is not coming to the lake anymore (that is $N=0$ ).

6. Solve the differential equation from question 5.

7. Determine time needed to reach the $(1-p)$ portion $\left(C(t) / C_{0}=1-p\right)$ of the initial concentration $C_{0}$.

After completing the project the students were asked to answer the questions below. The total number of students who completed the project was 147 in both countries. The number of students who answered the anonymous questionnaire was 63 so the response rate was $43 \%$. Participation in the study was voluntary.

Question 1. Do you find the project to be practical?
a) Yes
Please give the reasons:
b) No
Please give the reasons:

Question 2. Do you find the project to be relevant and useful for your future career?
a) Yes
Please give the reasons:
b) No
Please give the reasons:

The results in both universities were so similar that we decided to combine them. A brief statistics and common students' comments are presented below.

Question 1. Practical? Yes - 48\%

Selected students' comments were: "The models describe the real world”, “A good way of increasing students interest in the subject", "It was so helpful for my other subjects", "I didn't realize modelling is used for fishing quotas. It also helped me realize the effects of sneaky illegal fishing (which most of us have done)".

Question 1. Practical? No-52\%

Selected students' comments were: "It is not possible to calculate the nature", "It did give a practical situation but you bearly think about that at all when doing the assignment”.

Question 2. Relevant for your career? Yes - 35\%

Selected students' comments were: "Mathematics is the base needed to go into the Engineering World, so it will help a lot”, "In engineering, we will be dealing with these kind of situations", "We are more motivated to solve such real problems than working with dry examples", "Everything you learn is bound to be beneficial at some point".

Question 2. Relevant for your career? No - 65\%

Selected students' comments were: "I don't see how it relates to mechanical or electrical engineering” (most common comment), "I don't compute formulas, I have to calculate beams...”.

\section{The Second Study}


The second study is a case study based on the experimental course Mathematical Modelling of Survival and Sustainability taught to a mixture of year 2-5 engineering students in Germany by a visiting lecturer from New Zealand in 2006 and 2007. The course has a multidisciplinary character and is very practical. Matlab is used throughout the course. The expected students' benefits (learning outcomes) after completing the course are:

- Improving students' generic mathematical modelling skills

- Developing students' skills of analysing aspects of survival and sustainability of ecological, environmental, socio-economic and military systems

- Improving students' multidisciplinary and interdisciplinary competence

- Increasing students' confidence in using computer software

- Improving students’ conceptual understanding of related mathematics topics

- Enhancing students' ability to deal with real practical problems

- Developing students' team work skills

- Creating students' ethical responsibility to environmental issues

- Making connections to the local industry

- Enhancing students’ problem solving skills

The students solved a number of ecological and environmental models in their individual and group projects and also on the exam. They could have their group project based on a appropriate journal paper selected from the course website. They could also approach a local business/industry or contact a relevant department of the local dovernment to choose a real practical project based on the local data. One of the models is given below.

$\underline{\text { Populations of Birds and Insects on Poel Island in Mecklenburg-West Pomerania }}$

Populations of birds and insects on Poel Island are modelled by the following system of the equations:

$$
\begin{aligned}
& \frac{d x}{d t}=0.4 x-0.002 x y \\
& \frac{d y}{d t}=-0.2 y+0.000008 x y
\end{aligned}
$$

Questions:

1. Which of the variables, $\mathrm{x}$ or $\mathrm{y}$, represents the bird population and which represents the insect population? Explain.

2. Find the equilibrium solutions and explain their significance.

3. Find an expression for dy/dx and solve this separable differential equation by hand.

4. Use Matlab (pplane) to draw the phase trajectory corresponding to initial population of 100 birds and 40,000 insects. Use the phase trajectory to describe how both populations change with respect to time. 
5. Use part 4 to make rough sketches by hand of the bird and insect populations as functions of time. How are these graphs related to each other? Create those graphs with Matlab (pplane).

Suppose equations (1) are replaced by the following equations:

$$
\begin{aligned}
& \frac{d x}{d t}=0.4 x(1-0.000001 x)-0.002 x y \\
& \frac{d y}{d t}=-0.2 y+0.000008 x y
\end{aligned}
$$

6. According to equations (2), what happens to the insect population in the absence of birds?

7. Use Matlab (pplane) to draw the phase trajectory for equations (2) corresponding to initial population of 100 birds and 40,000 insects. Use the phase trajectory to describe how both populations change with respect to time.

After completing the course the students were asked to answer the question "Do you think this course is suitable for engineering students and if so, why?" There were 11 students in 2006 and 14 students in 2007 in the course. The response rate was 100\%. Participation in the study was voluntary.

The results in both years were very similar so we decided to combine them. All 25 students answered 'Yes' to the above question. The main two reasons were:

- Improving knowledge in mathematics, Matlab and mathematical modeling that is useful for engineering - 23 (92\%). Typical students' comments were: "You consolidate your mathematical knowledge", "Raise knowledge about differential equations and especially how to build them", "Increasing skills in Matlab”, "In my opinion many problems or predictions in the 'engineering world' could be handled/solved with the techniques that you can learn here", "Because you learned how to put some problems into a mathematical system", "To see new ways (models)", "In the course you can better make a statement for normal problems about the life", "Because I could improve my understanding for differential equations", "The mathematical models all around us and the true way for an engineer is to understand how a model from the nature reacts if you change one parameter".

- Practical and interesting - 10 (40\%). Typical students' comments were: “To get practical problems", "It is very important to use practical part in the course as it is done here to help students to understand what are they going to do in their future jobs", "Of course it deals not with typically engineering problems but after all it was an interesting subject", "Engineering students can apply their knowledge and broaden their horizon", "It is nice to see we can use differential equations in other areas", "I think that every subject which has a lot of practical things is very useful. This mathematical course was very useful for me and I think, that in our university everyone must study mathematics in this way". 


\section{Conclusions from Both Studies}

There is a big difference between the students' responses in the two studies about the relevance of the suggested context of applications. Only 35\% of the first-year students from the first study indicated that the environment/ecology context is relevant for their future career whereas $100 \%$ of year $2-5$ students from the second study commented that the course was suitable for engineering students. One of the reasons for such a difference might be the difference in maturity. Another reason might be the difference in students' mathematics background. It was reflected in the exam performance. In the first study, the pass rate of the first-year students in their maths courses was around $50 \%$. In the second study, the pass rate of the year 2-5 students in the modelling course was $100 \%$. Moreover, all 25 students from the second study received excellent or very good final grades. Their learning was measured through two individual projects, one group project and the final exam. Their oral group presentations were independently assessed by several lecturers. From informal talks to the students from the second study we received a strong indication that their enthusiasm and positive attitudes towards the course significantly contributed to their high performance in the course and very positive attitudes towards the unusual contexts. It was a risk to offer such nontraditional course to engineering students. In spite of concerns of some engineering staff and to their surprise the students were very positive about the course. They were mature enough to value the new knowledge in mathematics and modelling they received from the course that can be applied in engineering (92\%). They also enjoyed the practicality of the course that enhanced their problem solving skills (40\%). From informal discussions with the students we learnt that all expected learning outcomes were achieved to a significant extend. The main lesson for us as teachers was: students' feedback should be taken into account when designing curricula for their study.

\section{References}

Crouch, R. \& Haines, C. (2004). Mathematical modelling: transitions between the real world and the mathematical world. International Journal on Mathematics Education in Science and Technology, 35 (2), 197-206.

Galbraith, P. \& Haines, C. (1998). Some mathematical characteristics of students entering applied mathematics courses. In J.F. Matos et al (Eds) Teaching and Learning Mathematical Modelling. Chichester: Albion Publishing, pp77-92.

Gruenwald, N. \& Schott, D. (2000). World mathematical year 2000: Challenges in revolutionasing mathematical teaching in engineering education under complicated societal conditions. Global Journal of Engineering Education, 4 (3), 235-243.

Gruenwald, N., Sauerbier, G., Zverkova, T., Klymchuk, S. (2005). Using mathematical models of ecology in teaching first-year engineering mathematics. The New Zealand Mathematics Magazine, 42, 3, 11-23.

Haines, C. \& Crouch, R. (2001). Recognising constructs within mathematical modelling. Teaching Mathematics and its Applications, 20 (3), 129-138.

Klymchuk, S.S. \& Zverkova T.S. (2001). Role of mathematical modelling and applications in university service courses: An across countries study. In J.F. Matos et al 
(Eds) Modelling, Applications and Mathematics Education - Trends and Issues. Ellis Horwood, pp227-235.

Maull, W. \& Berry, J. (2001). An investigation of students working styles in a mathematical modelling activity’. Teaching Mathematics and its Applications, 20 (2), 78-88.

Nyman, A. \& Berry, J. (2002). Developing transferable skills in undergraduate mathematics students through mathematical modelling. Teaching Mathematics and its Applications, 21 (1), 29-45.

Zevenbergen R, Begg A (1999). Theoretical framework in educational research. In R.K. Coll et al (Eds.), SAME Papers. University of Waikato, New Zealand, pp170-185. 